\title{
IONIC MASS TRANSFER ON FIXED DISK AND CONICAL ELECTRODES UNDER STREAMING SOLUTIONS-II. EXPERIMENTAL APPROACH*
}

\author{
J. S. W. Carrozza, S. L. Marchiano, J. J. Podestá and
}

A. J. ARvía

Instituto Superior de Investigaciones, Facultad de Quimica y Farmacia, and Departamento de Ingenieria Quimica, Facultad de Ciencias Fisicomatematicas, Universidad Nacional de La Plata, La Plata, Argentina

Abstract-Ionic mass transfer on conical electrodes with axially streaming solutions is studied. The limiting current for different electrochemical systems was determined under experimental conditions chosen for testing the conclusion of the previous theoretical study.

The influence of the flow rate, the length of the cone, the angle of the cone, the viscosity of the fluid, the diffusivity of the component as well as the ratio of the maximum cone diameter to the width of the channel was determined.

The average rate equation under laminar conditions, is expressed by the dimensionless equation

$$
\mathrm{Sh}_{x}=0.80 \operatorname{Re}_{x}^{1 / 2} \mathrm{Sc}^{1 / 3} \text {, }
$$

where $X$ refers either the cone generatrix or the radius of the disk-type electrode chosen as the characteristic length, the Reynolds number being defined by means of the maximum flow rate. Experimental data agree with the theoretical prediction.

Résumé-Recherches sur le transfert de masse ionique sur électrodes coniques avec des solutions en mouvement axial. Pour différents systèmes électrochimiques, le courant limite a été déterminé dans des conditions expérimentales appropriées au contrôle d'une étude théorique préalable.

Les influences du débit, de la longueur du cône, de l'angle du cône, de la viscosité du fluide, de la diffusibilité du composant ainsi que du rapport entre le diamètre maximum du cône et la largeur du canal ont été déterminées.

L'équation de la vitesse moyenne sous des conditions laminaires, est exprimée par l'équation adimensionnelle

$$
\mathrm{Sh}_{x}=0,80 \mathrm{Re}_{x}^{1 / 2} \mathrm{Sc}^{1 / 8} \text {, }
$$

où $X$ se rapporte soit à la génératrice du cône, soit au rayon de l'électrode à disque choisie comme de longueur caractéristique, le nombre de Reynolds étant défini au moyen de la vitesse maximum d'écoulement. Les résultats expérimentaux sont en accord avec les prévisions théoriques.

Zusammenfassung-Man untersuchte den Stofftransport an achsial angeströmten, konischen Elektroden durch Grenzstrommessungen mit verschiedenen elektrochemischem Systemen.

Es wurde der Einfluss der Strömungsgeschwindigkeit, der Länge und des Spitzenwinkels des Konus, des Verhältnisses zwischen Basisdurchmesser und Kanalweite sowie der Viskosität und des Diffusionskoeffizienten ermittelt.

Unter laminaren Strömungsbedingungen ergibt sich die folgende dimensionslose Beziehung

$$
\mathrm{Sh}_{x}=0,80 \mathrm{Re}_{x}^{1 / 2} \mathrm{Sc}^{1 / \mathbf{a}} \text {, }
$$

wobei $X$ sich entweder auf die Mantellinie des Konus oder auf den Radius der Scheibe als charakteristische Länge der Elektrode bezieht und die Reynolds-Zahl mit der maximalen Strömungsgeschwindigkeit gebildet wird. Die experimentellen Ergebnisse stimmen gut mit der Theorie überein.

\section{INTRODUCTION}

IN PART I $I^{1}$ an equation for the rate of the diffusional flux was given, for systems comprising either fixed disk or cones placed in a channel of infinite width with an axial fluid stream at uniform velocity. That equation is valid for laminar flow, which

* Manuscript received 25 July 1966. 
is expected to prevail only up to a certain critical value of Reynolds' number. The equation given in terms of dimensionless numbers is

$$
\mathrm{Sh}_{X}=0.80 \mathrm{Re}_{X}^{1 / 2} \mathrm{Sc}^{1 / 3}
$$

where $\mathrm{Sh}_{X}, \mathrm{Re}$ and $\mathrm{Sc}_{X}$ are Sherwood, Reynolds and Schmidt numbers respectively, defined as

$$
\mathrm{Sh}_{X}=\frac{k X}{D_{i}} ; \quad \mathrm{Re}_{X}=\frac{U X}{\nu} ; \quad \mathrm{Sc}=\frac{\nu}{D_{i}} .
$$

$k$ is the mass transfer rate constant in $\mathrm{cm} / \mathrm{s}, D_{i}$ is the diffusion coefficient of species $i$ in $\mathrm{cm}^{2} / \mathrm{s}, \nu$ is the kinematic viscosity in $\mathrm{cm}^{2} / \mathrm{s}, U$ is the velocity of the incident flux in $\mathrm{cm} / \mathrm{s}$, which should be defined according to the experimental conditions, and $X$ is the characteristic length corresponding either to the cone generatrix or the radius of the disk. The numerical coefficient of (1) was found to be practically independent from the angle of the working surface.

An equation of the form indicated by (1) was formerly proposed in a hydrodynamic voltammetry study on conical platinum micro-electrodes, ${ }^{2,3}$ by extension to mass transfer of the expression resulting from the resolution of the heat-transfer problem for boundary conditions similar to those of the system employed.4 Defining Sh and Re in the usual way and taking as characteristic length that along which the liquid flows, the following equation resulted,

$$
\mathrm{Sh}=\frac{4}{3 \sqrt{ }(3)} \operatorname{Re}^{1 / 2} \mathrm{Sc}^{1 / 3}
$$

The numerical coefficient of (3) is $0 \cdot 769$, very close to the value found through the solution of the mass-transfer differential equation.

To test the validity of these equations it is indispensable to obtain experimental information covering as far as possible the whole set of variables involved in the theory. So, the flow rate, the length and the angle of the cone, the viscosity of the fluid, the diffusivity of the component as well as the ratio of the maximum cone diameter to the width of the channel where the liquid flows, were in due course suitably changed.

\section{Electrolysis cell}

\section{EXPERIMENTAL}

The electrolysis cell is shown in Fig. 1. The cylindrical metallic tube was of copper or nickel-plated copper and it constituted a part of the flow circuit as well as the counter-electrode. The working electrode was axially placed and centred in the tube, being kept in position by means of a specially designed holder. A conical working electrode mounted on a Lucite rod either of copper or nickel-plated copper was used, depending upon the electrochemical reaction to be studied. Electrodes of different dimensions were employed as shown in Table 1.

Just in front of the conical electrode a hole of $0.3 \mathrm{~mm}$ diameter was drilled through the counter-electrode to allow contact with a suitable reference electrode placed in a conventional container. The electrolysis cell was mounted vertically, the liquid flowing upwards.

The rest of the flowing circuit was formed by a glass container dipped into a thermostat and an all-glass pumping device driven by an ac-controlled motor. The 


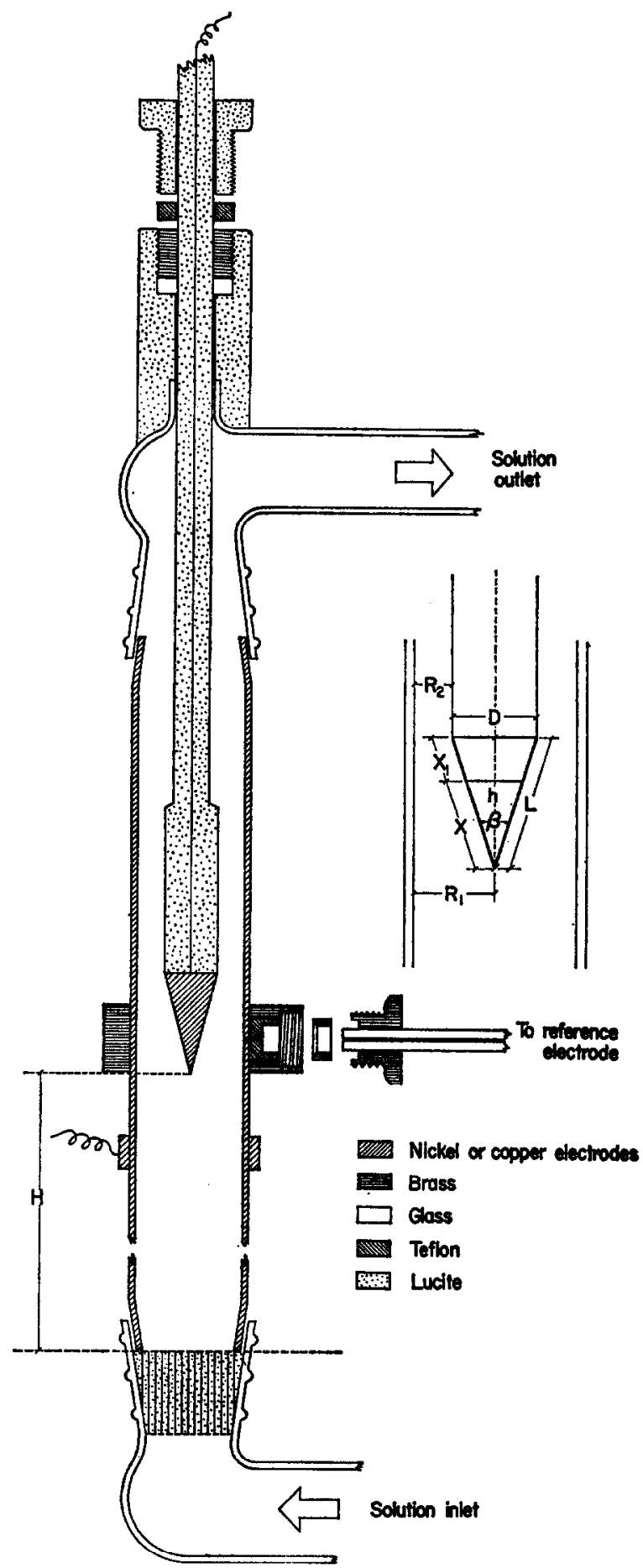

FIG. 1. Scheme of the electrolysis cell and details of the working electrode. 
TABLE 1

\begin{tabular}{|c|c|c|c|c|c|}
\hline Electrode & $\begin{array}{l}\text { Angle } \\
\text { degree }\end{array}$ & $\underset{\mathbf{c m}}{X}$ & $\begin{array}{l}X_{1} \\
\mathrm{~cm}\end{array}$ & $\underset{\mathrm{cm}^{2}}{S}$ & material \\
\hline 1 & 180 & 0.63 & - & 1.24 & $\mathbf{N i}$ \\
\hline 2 & 135 & 0.68 & - & 1.35 & \\
\hline 3 & 90 & 0.89 & - & $1 \cdot 76$ & \\
\hline 4 & 75 & 1.03 & - & 2.04 & \\
\hline 5 & 30 & $2 \cdot 46$ & - & 4.87 & \\
\hline 6 & 30 & 0.50 & 2.00 & 0.27 & \\
\hline 7 & 30 & 0.91 & 1.54 & 0.73 & \\
\hline 8 & 30 & 1.57 & 0.80 & $2 \cdot 10$ & \\
\hline 9 & 80 & 0.75 & - & $1 \cdot 12$ & \\
\hline 10 & 80 & 0.56 & - & 0.64 & \\
\hline 11 & 60 & 0.55 & - & 0.45 & \\
\hline 12 & 60 & 0.43 & 一 & 0.30 & \\
\hline 13 & 60 & 0.35 & - & 0.15 & $\mathrm{Ni}$ \\
\hline 14 & 80 & 0.97 & - & 1.92 & $\mathrm{Cu}$ \\
\hline
\end{tabular}

flow rate was read with a conventional flowmeter and it was adjusted as usual. The temperature of the solution was read just after passing the electrolysis cell. Current/ voltage curves were obtained either from point to point or continuously with a conventional circuitry.

\section{Working conditions}

The following solutions were employed: (i) equimolar solutions of potassium ferro- and ferricyanide in $2 \mathrm{M}$ sodium hydroxide and (ii) solutions of copper sulphate in $1.5 \mathrm{M}$ sulphuric acid. Glycerine was added to the latter up to $5 \mathrm{M}$ concentration. Solutions were prepared and de-aerated as earlier described. In the first case, the redox reaction

$$
\mathrm{Fe}(\mathrm{CN})_{6}{ }^{3-}+\mathrm{e}=\mathrm{Fe}(\mathrm{CN})_{6}{ }^{4-}
$$

in both directions was studied on activated nickel working electrodes. In the second case, the electrodeposition of copper was studied on polished copper electrodes, the overall reaction being

$$
\mathrm{Cu}^{2+}+2 \mathrm{e}=\mathrm{Cu} \text {. }
$$

In both systems the concentration of the reacting species was modified from 0.01 to $0.1 \mathrm{M}$. The kinematic viscosity of the copper sulphate solutions ranged from $1 \cdot 17 \times$ $10^{-2}$ to $4.26 \times 10^{-2} \mathrm{~cm}^{2} / \mathrm{s}$.

The average flow rate referred to the cross-section of the counter-electrode varied from 1.88 to $25 \mathrm{~cm} / \mathrm{s}$. Experiments were performed at temperatures from 20 to $40^{\circ} \mathrm{C}$, most of the results being obtained at $25^{\circ} \mathrm{C}$.

\section{RESULTS AND INTERPRETATION}

In any electrochemical reaction, under convective diffusion control, the maximum mass transfer flux is related to the limiting current density, $I$, by the expression

$$
j_{\max }=\frac{I_{\mathrm{L}}}{n_{i} F S}=k C_{i}{ }^{0},
$$

where $n_{i}$ is the number of electrons participating in the reaction, $F$ Faraday's constant, $S$ the geometrical electrode area, $k$ the average mass-transfer rate constant and $C_{i}{ }^{0}$ 
the concentration of the diffusing species in the bulk of the solution. Equation (4) is valid if an excess of supporting electrolyte is present in the system.

Limiting current densities required to evaluate the rate constant were obtained from current/voltage curves. Typical curves are shown in Figs. 2 and 3.

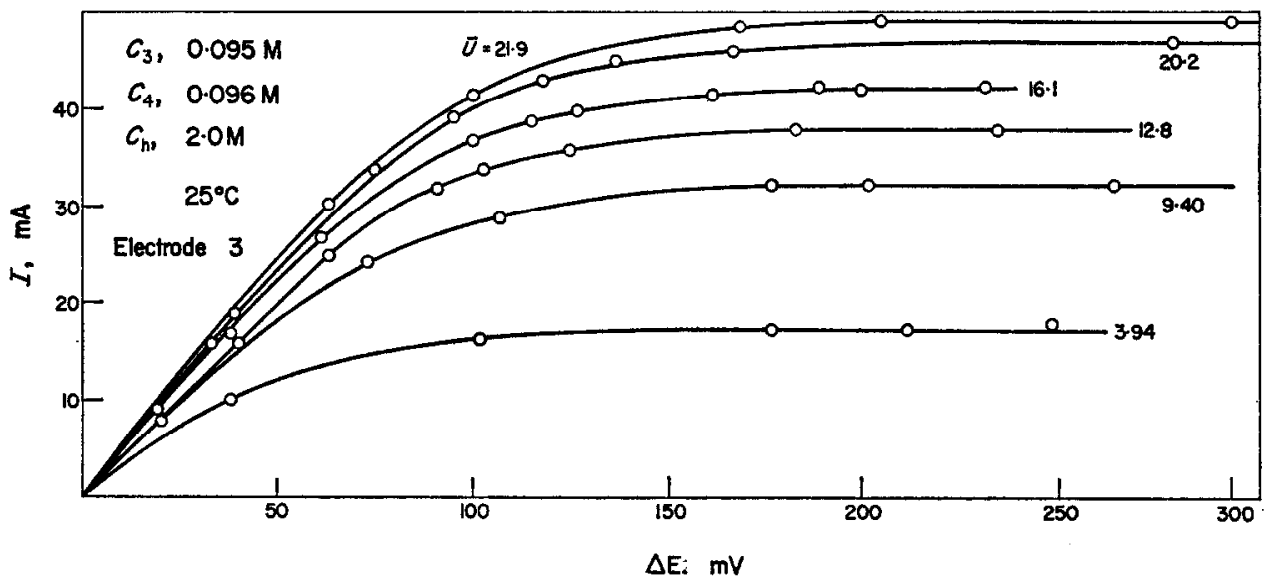

FIG. 2. Current/voltage curves for the reduction of ferricyanide ion. Average flow rates, $\bar{U}$, are in $\mathrm{cm} / \mathrm{s}$.

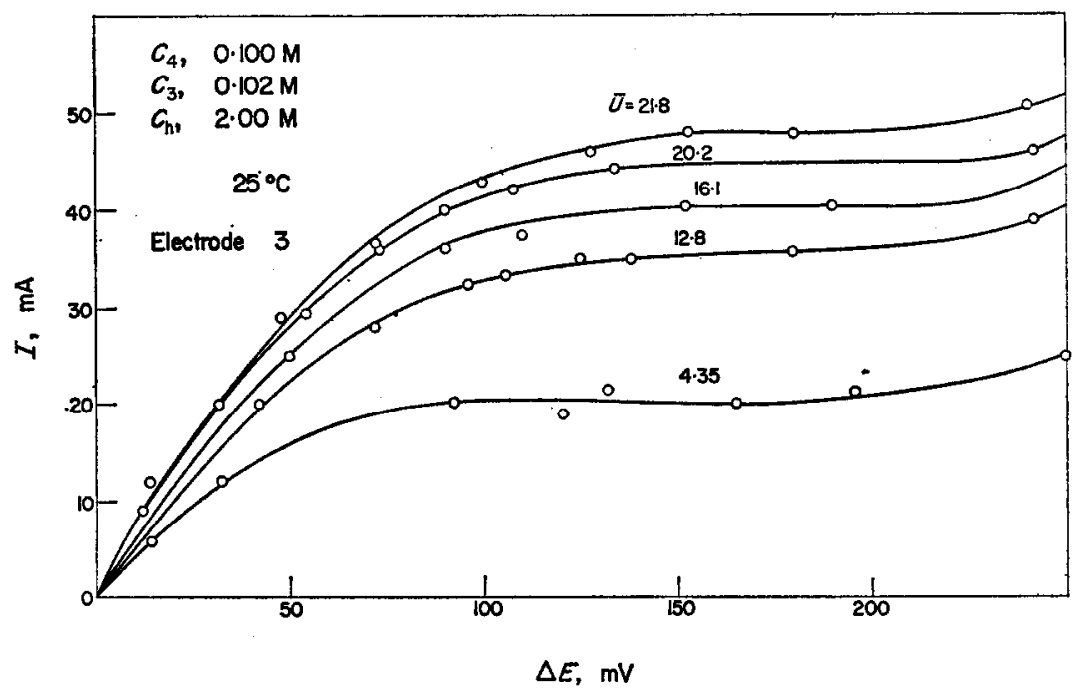

FIG. 3. Current/voltage curves for the oxidation of ferrocyanide ion. Average flow rates are in $\mathrm{cm} / \mathrm{s}$.

\section{The effect of the flow rate}

As indicated in Figs. 2 and 3, the limiting current density increases with the flow rate of the electrolyte solution. The limiting current density is linearly dependent on the square root of the flow rate, as shown in Figs. 4 and 5. This type of plot also shows that the limiting current density at constant flow rate depends on the particular conical electrode employed. Taking into account the electrolysis cell design and the 


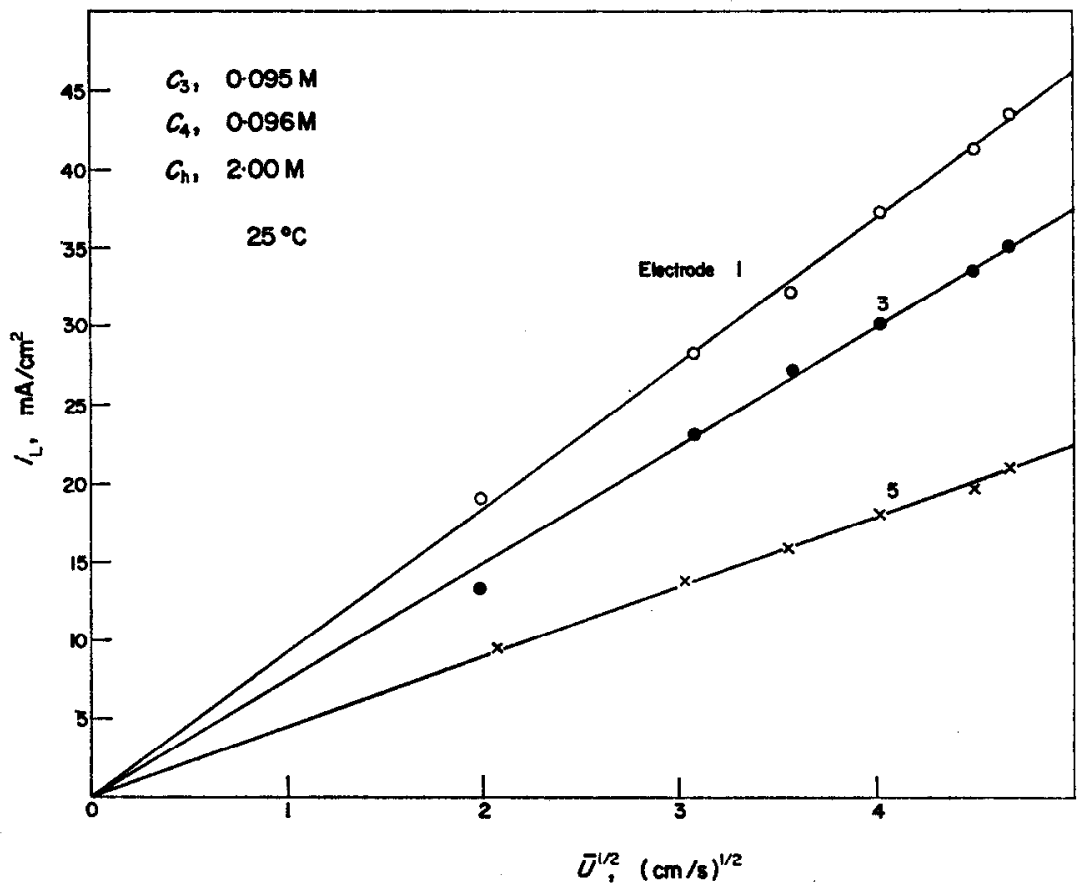

Fio. 4. Plot of the limiting current density $v s$ the square root of the average flowing rate for the reduction of ferricyanide ion.

positions of the cone, the flow velocity at the location of the working electrode is required in order to evaluate the actual significance of the flow rate on the masstransfer rate. If the Poiseuille profile in the counter-electrode is fully developed, the maximum velocity, which is twice the average velocity experimentally determined, is required to compute Reynolds' number.

The velocity profile at the counter-electrode is fully developed after a certain entrance length, which is a function of the diameter of the tube and the Reynolds' number. It was therefore interesting to examine the influence of the velocity-profile

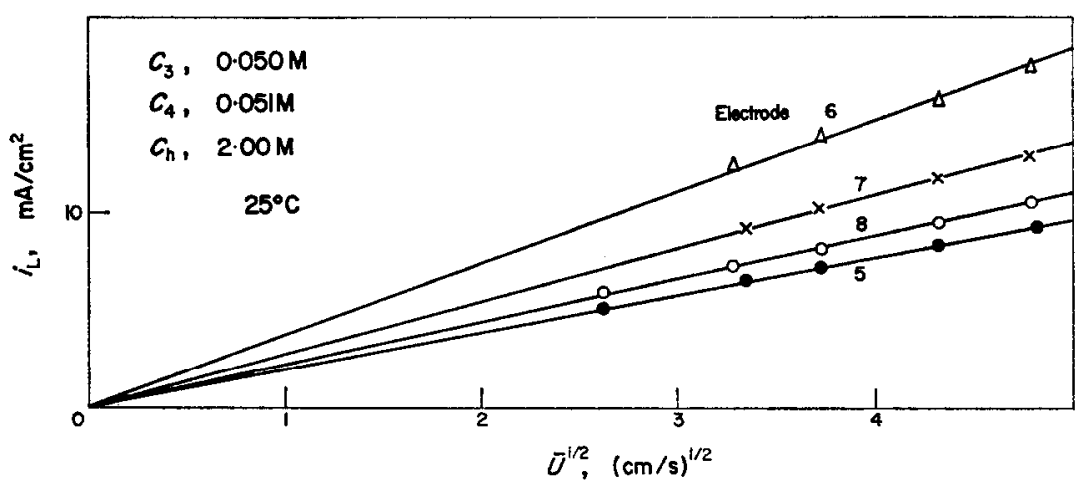

Fig. 5. Plot of the limiting current density $v$ s the square root of the average flowing rate for the oxidation of ferrocyanide ion. Influence of the length of the cone. 
development at the counter-electrode on the processes occurring at the working electrode. Experiments performed by placing the working electrode at depths varying from 5 to $20 \mathrm{~cm}$ within the counter-electrode show no detectable influence within the expected degree of accuracy. Therefore, in the processing of experimental data obtained with the tubular cell, the maximum flow velocity is considered as being that actually effective in the convection.

\section{Dependence on the $v / D$ ratio}

To study this effect copper-sulphate-sulphuric-acid solutions with different concentrations of glycerine were used. A copper electrode with a fixed geometry was employed. The limiting current densities were determined, the whole current/voltage curves being known previously, by performing measurements in a short time while polarizing the working electrode at a fixed potential, in order to avoid as far as possible any distortion of results due to an appreciable change of electrode surface.

The dependence of the rate of mass transfer on Schmidt's number was found by plotting $\log \mathrm{Sh} v s \log \mathrm{Sc}$ at constant Re. The data were previously processed graphically by plotting $\log$ Sh $v s \log \operatorname{Re}$ for the different solutions, since the experimental data were not suitable for direct plotting, as formerly indicated. Results are shown in Fig. 6; each straight line corresponds to constant Re. It can be concluded that the exponent of Sc is $1 / 3$. This dependence seems valid up to Sc of $3 \times 10^{4}$. Values of the diffusion coefficient for the systems employed were taken from the literature. ${ }^{0-9}$

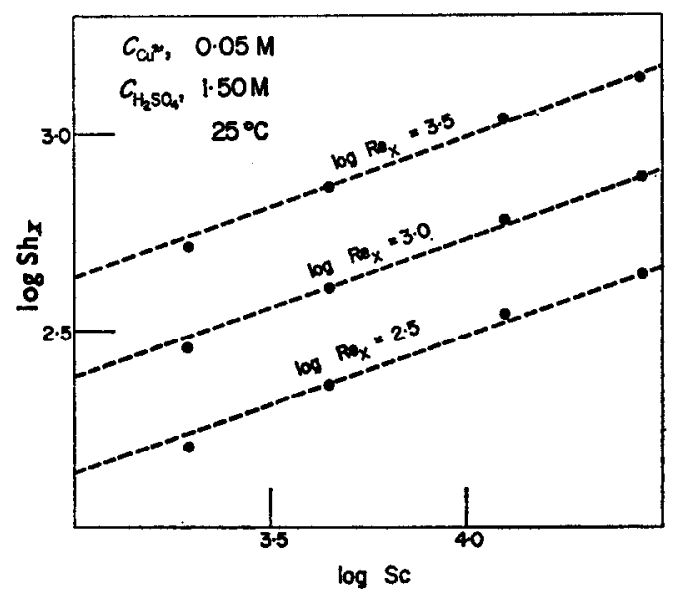

Fio. 6. Influence of Schmidt's number. The slope of the straight lines is 1/3.

\section{Influence of the length of the cone}

This influence was studied with electrodes of constant angle. As can be predicted, if hydrodynamic and diffusional profiles originate at the cone vertex, the ionic masstransfer rate should increase when the length of the electrode decreases. In Fig. 7 $\log i_{\mathrm{L}}$, calculated by means of (4), has been plotted against $\log X$, for a constant angle, yielding a slope close to $-1 / 2$. 


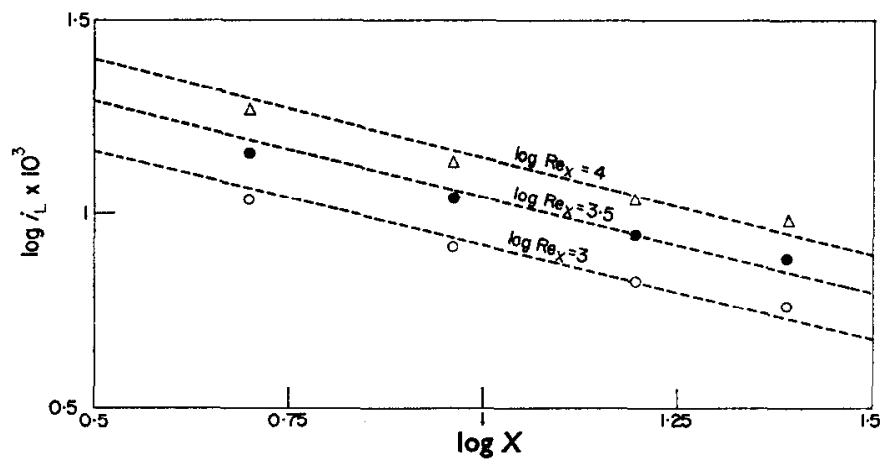

Fig. 7. Influence of the cone length. The stope of the straight lines is $-1 / 2$.

\section{Influence of the cross-section}

The ratio between the diameter of the counter-electrode to the diameter of the cone base was varied from $1 \cdot 7$ to $7 \cdot 0$. No appreciable effect of this ratio on the masstransfer rate was observed. This finding is confirmed by the fact that those data can be satisfactorily correlated with the general equation indicated below.

\section{Influence of concentration}

Equation (4) predicts a linear relationship between mass-transfer rate and concentration of the diffusing species; this was also verified within the concentration range employed, as shown in Fig. 8.

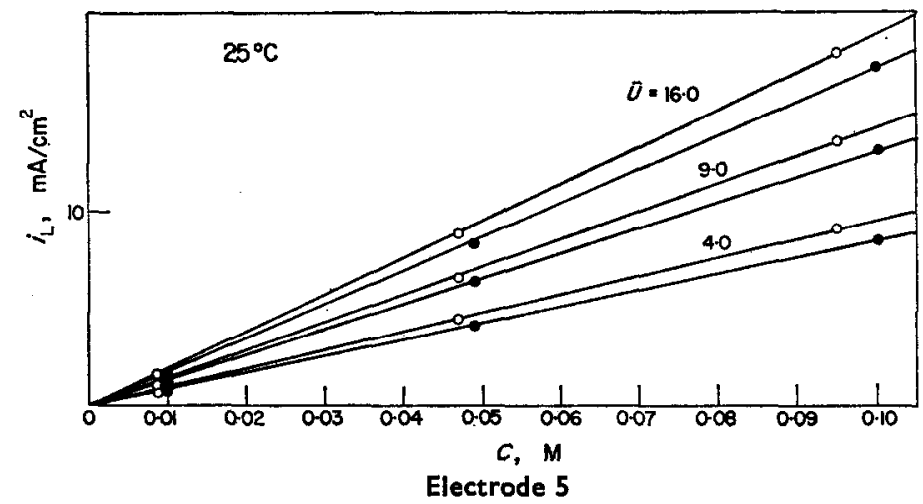

Fra. 8. Dependence of the limiting current density on the concentration of the reacting species. O, reduction of ferricyanide ion; 9 , oxidation of ferrocyanide ion.

\section{Influence of temperature}

Temperature influence is shown in Fig. 9 by plotting $\log k v s 1 / T, T$ being the temperature in ${ }^{\circ} \mathrm{K}$. Each straight line corresponds to a constant flow rate. The experimental activation energy calculated from Fig. 9 for the ferro-ferricyanide redox couple is $3.8 \pm 0.2 \mathrm{Kcal} / \mathrm{mole}$. The temperature effect was required to refer all experimental results to $25^{\circ} \mathrm{C}$.

\section{Correlation of results}

The experimental results, referred to $25^{\circ} \mathrm{C}$, were plotted according to (1), keeping in mind the previous considerations in defining Reynolds' number. 


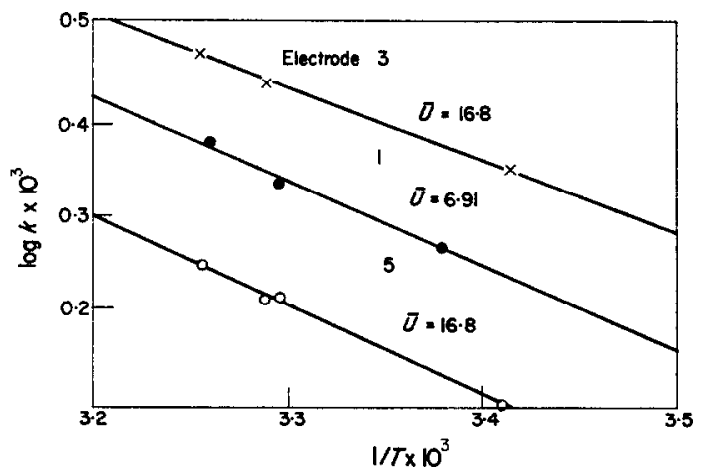

Fig. 9. Arrhenius plot of the ionic mass transfer rate constant for the ferro-ferricyanide system.

The straight line goes in each case through the origin, and its slope, within the scatter of results, is independent of the electrochemical system, the angle and the design of the conical electrode. Taking into account the slope of the dotted line and the experimental data, a remarkable coincidence with the prediction of theoretical equation described in Part $I$ is observed.

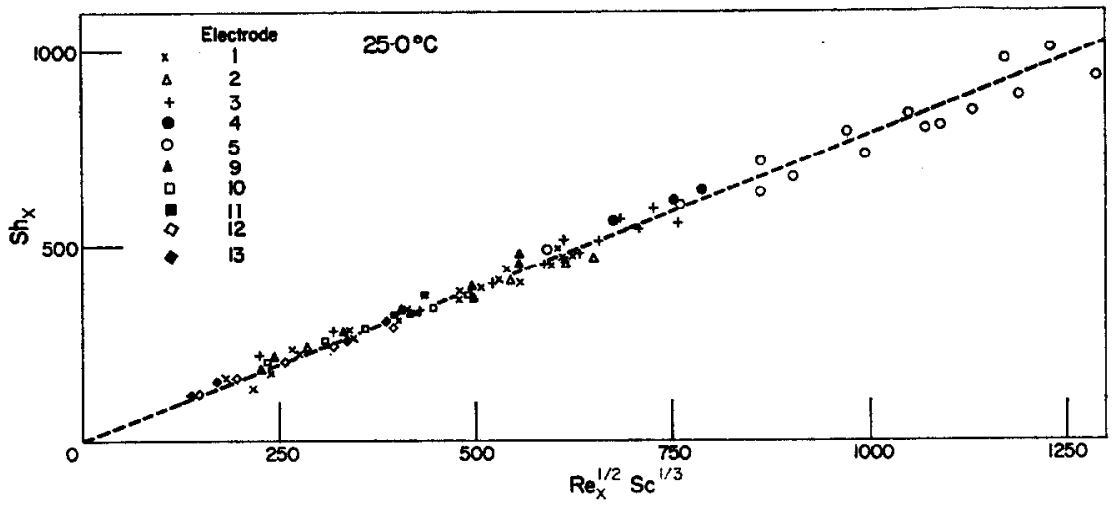

Fig. 10. Test of the correlation for the reduction of ferricyanide ion.

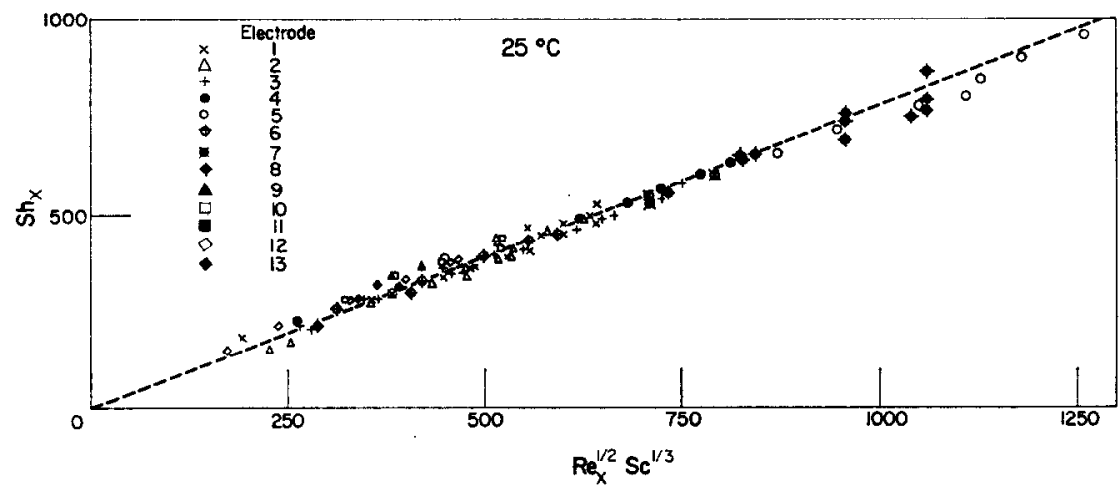

Fig. 11. Test of the correlation for the oxidation of ferrocyanide ion. 


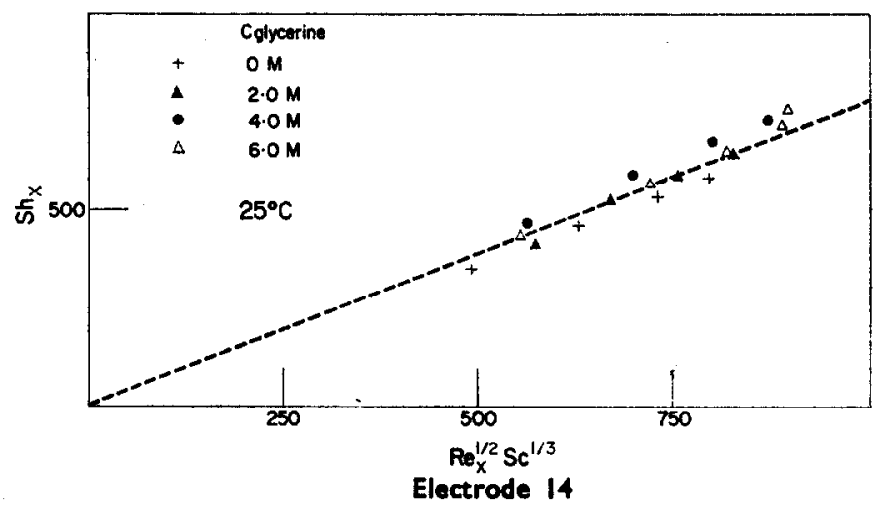

Fig. 12. Test of the correlation for the reduction of copper ion.

The points in Figs. 10-12 refer to more than 90 per cent of the experiments performed. A few experiments have been disregarded, with the redox ferro-ferricyanide system; their failure was probably due to faulty activation of the nickel electrodes.

\section{Analysis of errors}

The errors involved in this work were evaluated as indicated previously. ${ }^{10}$ The maximum calculated error amounts to 10 per cent, although the error of results shown in Figs. 10-12, as compared to (1), is lower than that figure.

\section{CONCLUSIONS}

The relationship provided by the theoretical approach to the problem of ionic mass transfer on conical electrodes ${ }^{1}$ as well as by the deduction from the analogous heat-transfer problem ${ }^{2}$ is evidently satisfied. This is clearly shown when data obtained under very different experimental conditions are satisfactorily correlated with the same rate equation.

It is interesting to note that the mass-transfer rate is independent from the angle of the conical electrode, as predicted, since the numerical coefficient of the rate equation involves the product $\alpha^{1 / 3} / 3^{(m-1) / 2} \sqrt{ }[(m+1) / 2]$, which is practically constant for different values of $m$, as already indicated in Part $I .^{1}$

Another important fact to emphasize is related to the influence of the counterelectrode wall in the formation of the hydrodynamic profile on the working electrode and consequently, its effect on the mass-transfer rate. Experiments performed with constant angle electrodes of different generatrix and ratios between the active and inactive length from the electrochemical viewpoint, indicate no sensible influence of the counter-electrode wall. So, the maximum velocity of the profile affects mainly the convective contribution to mass transfer on the working electrode. The conclusion drawn in the present work can be extended to a free flux system, provided that the fluid velocity is properly defined. This possibility and further applications of this type of electrodes are considered in Part III. ${ }^{11}$

Acknowledgement-Partial support of this work from the Consejo Nacional de Investigaciones Cientiflcas y Técnicas of Argentina and a Fellowship granted to S. L. M. by the same Institution are acknowledged. 


\section{REFERENCES}

1. S. L. MARChIANo and A. J. ARví, Electrochim. Acta 12, 801 (1967).

2. J. JoRdan, R. A. JAVICK and W. E. RANZ, J. Am. chem. Soc. 80, 3846 (1958).

3. J. JoRDAN and R. A. JAVICK, Electrochim. Acta 6, 23 (1962).

4. H. A. Johnson and M. W. Rubesin, Trans. Am. Soc. Mech. Engrs 71, 447 (1949).

5. J. C. BazÁn and A. J. ARvía, Electrochim. Acta 9, 667 (1964).

6. M. Eisenberg, C. W. Tobias and C. R. WilKE, J. electrochem. Soc. 101, 306 (1954).

7. A. R. Gordon and A. Cole, J. phys. Chem. 40, 733 (1936).

8. J. C. BAZÁN and A. J. ARvtA, Electrochim. Acta 10, 1025 (1965).

9. A. J. Arvia, J. C. Bazán and J. S. W. Carrozza, Electrochim. Acta 11, 881 (1966).

10. J. C. BAzÁn and A. J. ARví, Electrochim. Acta 9, 17 (1964).

11. J. C. BazÁn, S. L. Marchiano and A. J. ARvía, Electrochím. Acta 12, 821 (1967). 